\title{
NGO's Intervention to Bring Change in the Society- A Case Study of 'SIRRA'
}

\author{
Laveena D’Mello \\ Assistant Professor, Social Work Department, Srinivas Institute of Management Studies, \\ Mangaluru, Karnataka-575001, INDIA \\ E-mail: lavynoronha@gmail.com
}

Type of the Paper: Case Study Article.

Type of Review: Peer Reviewed.

Indexed In: OpenAIRE.

DOI: http://dx.doi.org/10.5281/zenodo.580084.

Google Scholar Citation: IJCSBE

\section{How to Cite this Paper:}

D’Mello, Laveena. (2017). NGO’s Intervention to Bring Change in the Society- A Case Study of 'SIRRA'. International Journal of Case Studies in Business, IT and Education (IJCSBE), 1(1), 19-26.

DOI: http://dx.doi.org/10.5281/zenodo.580084.

International Journal of Case Studies in Business, IT and Education (IJCSBE)

A Refereed International Journal of Srinivas University, India.

(C) With Authors.

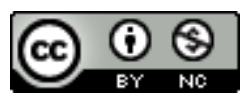

This work is licensed under a Creative Commons Attribution-Non Commercial 4.0 International License subject to proper citation to the publication source of the work.

Disclaimer: The scholarly papers as reviewed and published by the Srinivas Publications (S.P.), India are the views and opinions of their respective authors and are not the views or opinions of the S.P. The S.P. disclaims of any harm or loss caused due to the published content to any party. 


\title{
NGO's Intervention to Bring Change in the Society- A Case Study of 'SIRRA'
}

\author{
Laveena D'Mello \\ Assistant Professor, Social Work Department, Srinivas Institute of Management Studies, \\ Mangaluru, Karnataka-575001, INDIA \\ E-mail: lavynoronha@gmail.com
}

\begin{abstract}
Any organization, whether NGO (Non-Governmental Organization) or Government, involved in the rural or urban development is making concerted efforts in diverse activities. Some NGO's are involved in helping weaker sections of the society such as small and marginal farmers, agricultural labourers, reservation castes, while others engage in, setting up schools and hospitals in the rural areas, provision of better nutrition to children, health intervention, family welfare, organizing vocational training to enable youth and special programmes formulated for senior citizens. Srinivas Institute of Rural Reconstruction Agency (SIRRA) is one such NGO engaged in Rural Welfare activities for the past Ten years. This NGO is formed under the aegis of A. Shama Rao Foundation, which is well known in the field of quality education services, and sponsored over nineteen colleges. SIRRA has a team of experienced trainers and resource persons who would always guide the rural development activities in Dakshina Kannada District. With the rich knowledge, skills and contacts gained, SIRRA organized various programme and provides opportunity for student Social Workers to practice their field practicum. This was done in the collaboration with Srinivas Institute of Medical Science and Research centre, Mangalore. SIRRA organized number of community outreach programmes, medical camps, street plays, awareness programmes etc. for the disadvantaged sections of the society. This study explores the intervention activities and its impact on the society, through the case study.
\end{abstract}

Keywords: Non Government Organization (NGO), Government Organization (GO), Self Help Groups (SHG), Master of Social Work (MSW).

\section{INTRODUCTION :}

The urge for self management in different situations is a basic drive of human beings. Technology is the creative expression of this drive. It is both a liberating influence and a constraint depending on the specific situation. India has a rich tradition in Voluntary service. But the role of the Voluntary Organization in Social Welfare and Social Development is yet to be understood even after seven decades of planning. On the other hand, the quantified growth of voluntary organizations has been rather very fast. The establishment of autonomous national bodies such as the Central Social Welfare Board, Association for the Voluntary Associations in Rural Development etc opened many new avenues to this Voluntary Organization. Voluntary Organizations have been rendering services to individuals, groups and communities to a great extent in India. The physically handicapped, mentally retarded, socially mal-adjusted, underprivileged and ever exploited groups have been benefited by these voluntary organizations for which charity formed the basic philosophy. With this philosophy the philanthropists have turned their dreams into reality by way of starting voluntary social organizations such as hospitals for the poor, day-care centers for the needy children, rehabilitation centers for the handicapped etc.

An NGO's level of operation indicates the scale at which an organization works, such as local, international or national. Professor Peter Willetts, from the University of London, argues the definition of NGOs can be interpreted differently by various organizations depending on a situation's 
context. He defines an NGO as an independent voluntary association of people acting together on a continuous basis for common purpose. In this view, two main types of NGOs are recognized according to the activities they pursue: operational NGOs that deliver services and campaigning NGOs. The ultimate goal of any organization is the development and economic growth. In this regard the objectives are to increase the availability and widen the distribution of basic life sustaining goods such as food, shelter, health and protection; To raise standards of living, including higher incomes, more jobs, better education and a greater attention to cultural and humanistic values; To expand the range of economic and social choices available to individuals and nations by freeing them from servitude and dependence [5, 6].

\section{ORGANIZATION :}

Many writers have attempted to state the nature, characteristics and principles of organizations in their way. For instance, to the sociologist, organizations means a study of the interaction of the people, classes or the hierarchy of an enterprise; to the psychologist, organization means an attempt to explain, predict and influence behavior of individuals in an enterprise, to a top executive, it may mean the weaving together of functional components in the best possible combination so that an enterprise can active its goals. Organization is the establishment of the formal and/or informal structure of authority through which the work is sub-divided, arranged, defined and coordinated for the defined objective [4]. The formal and/or informal organization are designed to achieve social welfare objectives by systematically coordinating the work of numerous personnel, consciously or unconsciously, covertly or overtly directed by some theoretical framework appropriate to meet the welfare needs of the target group. According to Dimock \& Dimock (1964) "Organization is the systematic bringing together of interdependent parts to form a unified whole thought which authority coordination and control may be exercised to achieve a given purpose.... Organization is both structure and human relations" [5]. The organization follows a system of communication to reach all. Organizations are not just a structure, it actually accepts a structure for the human beings who directs, organize and who actually do the work in order to achieve the objectives of the Agency. Firstly, the organizational variables are numerical and their inter-relationships are complex. Hence the selection and conceptualization of key variables for empirical testing has been a persistent problem in the field of organizational research. Secondly, often organizational terminologies are subject to a variety of interpretations depending on the setting in which the research is conducted. Thirdly, the results of organizational research have not yielded clearly defined conceptual frame work which can explain everything. Therefore, no single approach is universally accepted by organization investigators. The general characteristics of the organization are the Division of labour, power, and communication responsibilities that is not random or traditionally patterned, but deliberately planned to enhance the realization of specific goals; The presence of one or more power centers to control the concerted efforts of the organization and direct them towards its goals, as well as to review continuously the organizations performance and repeater its structure where necessary, to increase its efficiency, and; Substitution of personnel i.e., the removal of unsatisfied persons and the assignment of other to their tasks, as well as the recombination of personnel through transfer and promotion [1-2].

\section{VOLUNTARY ORGANIZATION :}

Voluntary agencies and non-official organizations are treated as one and the same. This may not be so. All non-official organizations are not necessarily voluntary. Voluntary organizations are spontaneous in their origin where as non-official agencies may also be government sponsored. It may be useful to draw a distinction between voluntary agencies and non-governmental agencies, whereas voluntary organizations are spontaneous in their origin, non governmental agencies may be sponsored by government. Although agencies like All India Women's Conference, Indian Council of Child Welfare, etc. are voluntary, yet project implementing committees appointed by the Central Social Welfare Board to run welfare extension projects and committees for running aftercare homes appointed by the state governments, though constituted primary of voluntary workers are not voluntary agencies but are known as non-official agencies, since theses agencies do not come into existence voluntarily but are sponsored and substantially funded by the government [4]. 
According to Kothari "Those initiatives that are struggling for social Justice through cultural and political means and for structural charge towards that end entail Voluntary organizations”. Voluntary Organizations can be defined as groups working at the macro levels in localized settings for and with the poor, marginalized and the Oppressed section of society, whether rural or urban. The various objectives of Voluntary organizations are; empower mental of the poor and oppressed; the building and strengthening of people's organization; the strengthening and re-energizing of social movements and; the promotion of democratic practices and process.

\section{VOLUNTARY ORGANIZATIONS IN PRESENT SOCIETY :}

As per the proceedings of National Assembly of Voluntary organizations, is to promote a balance and stable development a sustainable development form below; to empower women, dalits and tribal and urban poor. Struggle against fundamentalism and communalism; to promote accountability and transparency in all spheres of activities including political activity; while maintaining a separate identity, work with the government; to educate, organize and agitate; to strength against economic globalization; to form value based leadership; to promote networking among Voluntary organizations with a common focus; to empower the people from below and take to advocacy from above; to encourage self rule for the tribal and panchayat Raj system for others; to take development programmes and the public distribution system to the people; to integrate the economic empowerment programme around the people- income generating again should ensure that the profit goes to the people, training of people etc; to create a common platform at the regional and local levels; Promote participatory structures with and view to enter into dialogue with the people and government.

\section{METHODOLOGY :}

Aims and Objectives of the study: The main aim of the study is to know NGO's intervention to bring change in the society. Keeping this broad perspective in mind the study explores the intervention activities of SIRRA, a NGO and its interventions impact on the society. A Case study method was used.

Institution Profile: Srinivas Institute of Rural Reconstruction Agency (SIRRA), established in 2003, Registered in 2004. The founder President is Mr. A. Ragavendra Rao F.C. (President of A. Shama Rao Foundation, Mangalore). The office is situated at Srinivas Building, G.H.S. Road, Mangalore 575 001. The Area of Work is Dakshina Kannada, Udupi \& Kasargod Districts. The target Audiences are Women, Youth, Children, Weaker Section and General Public. The vision is to improve the standard of living of the under privileged and promote their empowerment. And the mission is to facilitate sustainable development through participatory community driven activities. The main objectives of this NGO are: To promote active participation of community for better qualitative human resource development; To provide essential services in the field of health, education, economic development, social development and spiritual Development; To facilitate the empowerment of the under privileged in the process of social development; To undertake research work with regard to socio-economic issues; Capacity building of poor communities to facilitate them in improving their living conditions; To assist communities in sustainable development and management of natural resources; To create awareness among the masses about the importance of education, health, good sanitation practices and communal harmony and to have Dialogue and networking with likeminded voluntary organizations.

\section{INTERVENTION ACTIVITIES :}

The activities which are undertaken during the recent year's are- raised wide propaganda in the village surrounding Mukka, Community Outreach program and Awareness generation programme and also launched Health card at Srinivas Hospital, Mukka for the BPL families, with Srinivas Medical College and Super Specialty hospital and patients were treated in the Camp free of cost. The glimpse of the activities is as follows.

- Free Medical camps in Mangalore and the target area: Free Medical camp organized at various places, Schools and panchayat level in collaboration with Srinivas Institute of Medical Science and research Centre, Mukka. Community Health awareness campaign was 
conducted by the agency with the help of MSW students. Every Sunday on regular basis, community level medical camps were organized with the collaboration of panchayat, Schools, Anganwadies, local clubs, Rotary and Lions Club, Church and Mosques and Volunteer of the locality. Preference will be given for the community involvement in giving publicity in the locality, provision of place and necessary arrangement to conduct the camp successfully. A team of Doctors from all the Departments of the Hospital like Pediatric, Ophthalmology, General Medicine, Gynecology, Skin and Surgery are attending the camps. ECG is taken on the spot in the camp and report is also given immediately. Free Transport, Publicity by banners and Pamphlets, Medical check-up, Medicine etc was provided during the camp. Similarly follow-up camp at Hospital was conducted for further treatment and free transport was provided to the needy patients. Camp patients have special consideration in the hospital with special deduction in the surgery, Medicines and other medical treatment. All these have done under SIRRA with the collaboration of Srinivas Hospital.

- Health Insurance: Health insurance was provided to the families especially in the area of Lingappaiyana Kadu, Mulki, K.S. Rao Nagar, Karnad, Mulki. 460 BPL families were identified. Follow-up of the programme was done by the Hospital staff and the insurance company. SIRRA intended to reach 1000 BPL families in the next year and cover with Health insurance. Specialize and executive check-ups are the part of the programme.

- Medical Clinic was started at Kilpady Grama Panchayat on regular basis on Every First Wednesday of the month. This will benefit for the people of Kerekadu, Kenchan Kere, Angara Gudde and Kilpady area near Kinnigoli. Also planning to start clinics at four identified areas.

- Blood donation camp: Campaign on blood grouping for its sister institutions was conducted regularly. The data base was collected from each student. Whenever there is an emergency, Hospital as well as needy patient party can get blood from the volunteers and donors. Volunteers were given awareness on requirement for the donors, importance of blood donation etc.

- School outreach programmes: The organization planned and implemented regular school outreach programmes especially for Government and Residential schools for disadvantage sections of the society, through free health checkups, personality development, improving leadership qualities, Life skills, awareness programmes, celebration of national festival, children's day etc., about 20 schools and more than 2000 students were benefited.

- Blood grouping camps for Government Primary School and the residential schools for disadvantage sections of the society: It is now mandatory for all the schools to give ID card for the school children in which they have to mention their blood group. So there was a request from the Head Masters/Mistresses of various schools to conduct free blood grouping camps. SIRRA organized number of Free Blood grouping camps in the hospital, as well as in their respective schools. Many schools of the locality are benefited out of this.

- General check-up for School Children: General check-up for school children of Mukka and surrounding area was conducted. The MSW students have organized this programme under SIRRA with the collaboration of Srinivas Hospital. Free check-up and medicines are provided for the school children. Follow up was done at Hospital.

- Shramadhan at Bolar: NGO is working in the adopted area and organized many awareness programmes and sramadaan (free labour) in the locality. MSW students have organized Shramadhan programme at Babbarya Temple, Bolar, Mangalore. Students, Social workers, the local leaders and the community people were involved in the cleaning of Temple square and the surrounding area. Health awareness, community integrity and role of social workers in the community were highlighted during programme.

- Picnic for the inmates of Prashanthi Nivas: Agency is collaborating with other NGO's by supporting them in organizing programme. Picnic for the inmates of Prashanth Nivas was organized in two batches for mentally challenged women. They were taken to Thannirbavi, Mulki retreat centre and Infant Jesus shrine, Bilarnakatte. For both these picnic two busses were provided through A. Shama Rao Foundation. Social worker planned the outing so 
effectively was organizing cultural event, spot games and entertainment and were encouraged with prize distribution.

- Women's Day celebration: World women's day was celebrated on $8^{\text {th }}$ March every year meaningfully by organizing the programme. On this day, women's problems and situation were discussed in detail. Theme will be taken based on the present day's need and the situation. Special lecture on 'Women and Mental Health', "Status of women” challenges etc were discussed. Awareness was created and importance will be given on women empowerment.

- World Health day Celebration: the world health day was celebrated regularly under SIRRA with the collaboration of District medical superintendent, Health Department and DHO. Medical officer discussed the theme given by World Health Organization (WHO) the theme for the year 2013 was to prevent the Hypertension (BP). The causes and the consequences of the hypertension were discussed elaborately and the prevention measures. Every year SIRRA will take initiative to address on different issues on world Health day and celebrate it meaningfully.

- Independence Day, Republic Day, Environment Day and Teachers Day celebrations: SIRRA Organized Various programmes for and with less privileged children and disadvantage sections of the society. Identified their unique talents and encouraged them. Social workers and staff of the agency were able to identify the needs of the children and uniqueness. Through the intervention activities like cultural events, sports, speeches make the celebration meaningful and able to light the spark of patriotism.

- Environment related programmes: SIRRA is Organizing Vanamahotsava programme with the help of NSS units of the colleges, within the campus of the colleges and its sister branches. This programme was organized with the collaboration with Forest Department. Average 100 saplings were planted every year.

- Participation in Self Help Group (SHG) meetings: SIRRA staff attending the ward sabha at various panchayath, Participation in the committee meeting, Sri Shakthi meetings, Attending Hindu Dharmik youth club meetings and youth club meetings at community level. This will help the agency to have good rapport in the community, to understand their needs and organize programmes accordingly. Women in the community are motivated to participate effectively in the meetings and encouraged to develop leadership qualities and the efforts to make them to have dignity at home and in the society. Survey and Health awareness: Survey on Hyper tension (BP) and Blood Sugar: Organized health promotion campaign by covering around 2000 population with the help of Survey on Hyper Tension (BP) and Blood Sugar from Mukka to Mulki area. Health awareness like Malaria, contagious diseases, Pediatric problems, general Health and hygiene, Dental awareness etc had been organized regularly.

- Life skill training programme for High school, PU and Degree students: SIRRA as qualified resource person's team and it organizes various programmes at school, college and community level and share information, knowledge and expertise in various issues especially on Life Skills. This will be conducted on the regular basis.

- Awareness Generation Programmes (AGP): SIRRA organized Number of programmes for the college students on various topics especially for the Associations, forums and Clubs at college level. This training was parted by the expert resource persons to improve their personality. Some of the programmes like human personality development programmes, effective communication, Positive attitude, Leadership, Positive Living etc.

- Guest lecture for NSS Volunteers: SIRRA Provides opportunity for the NSS Volunteers to organized their camps effectively by arranging Guest lecture, involving effectively in the camp and with special collaboration with the Agency and Department of Social work.

- Participation/Organization in Jatha, Peace March, Marathon for Youth -Run for India: SIRRA plays an active role in organizing awareness in general public by using various strategies. All the students take part actively in Jatha (marathon). 
- Programme for SHG's: SIRRA Organizes programme not only for college students but also for community level for the general public through SHG. Awareness Programme on right to information act, 2005: was organized for the students and women. Eminent resource persons were called and talk was arranged for the students. Awareness generation programmes were organized especially for women at community level.

- Street Play training and shows: Street play training was organized for the student social workers regularly every year. This was followed by putting up of shows in various places. Agency is organizing these shows based on the need of present society. Theme will be taken up on the issues like health, empowerment, importance of Education, evils of the society, alcoholism, empowerment of the women, awareness on HIV/AIDS and communicable diseases.

- Summer placement for MSW students at SIRRA and Srinivas Hospital: I MSW students after finishing their II semester, have opportunities to do their summer placement at Srinivas Hospital. They were assigned task under the guidance of the staff of Marketing Department, Medical and psychiatric Department, Community Medicine and Social work department in the Hospital.

- Practical training for Student Social Workers: SIRRA is accommodating more than 20 students every year and parting knowledge and training on field practicum. They were guided by experience, expert and trained field supervisors and Agency Supervisors. They organize orientation training, field placement, and community and Panchayats exposure, practicing Case work, Group work and training in counseling. They are involved in Survey, minor research projects, and taking group task in the community. The first year students are sent to open community to work with Anganwadies and Panchayats and the second years based on their specialization are placed in Hospital community medicine department and Medical and Psychiatric wards with experts. And the Community Development specializations are working with panchayats. So SIRRA work as Training centre of the budding professional Social workers. Many more activities, intervention programmes, surveys have been organized under SIRRA. With the help of management and team of experts, social workers and the staff, organization had taken initiative in bringing change in the society.

\section{IMPACT ON SOCIETY :}

Various Community intervention programmes had been conducted in the community for the needy people which has brought tremendous change in the approach and able build rapport with the community people. Community Organizer and the social worker pay regular home visit, selected needy cases from the community and tried to solve cases, conducted group activities to children and teenagers from nearing schools, participated in youth club and Self Help Group meetings, and regular community intervention programmes. Student's social workers are trained and enabled to become professional social workers at this centre. Opportunity was provided for the student's social workers to organize community outreach programmes under SIRRA. Programs- like Free eye test camp, Blood grouping and blood donation camp, Child nutrition \& Care, AIDS awareness camp, Activities with collaboration with other NGO's and Government Organizations, Health clinics at two places, General health camps, Free Medicine during the camp, Free registration for Camp patients, Free treatment, No bed charges or any charges and free food at General wards, Health insurance, Free transport for follow-up camp, Ambulance facilities at nominal rate for general public, Environment friendly programmes, Free vehicle facilities from community to Hospital for few identified areas, School outreach programme at Government residential school were conducted with the collaboration with Srinivas Hospital. These sister institutions of Srinivas Groups are the strength for SIRRA to mobilize resource from one centre to other for the benefit of the society.

\section{CONCLUSIONS :}

As the better community with full cooperation by the people yields good results and extends its wings to further development. Community development requires hard work, strong commitment self determination and focused mind. In this regard SIRRA as done spectacular works in the field of rural development such as community health, adult education, community organization, sangam- 
formation, promotion of Self Help Groups, school outreach programmes etc..Therefore this NGOs has played a remarkable role in the context of development.

\section{REFERENCES:}

[1] Bhatia Anju. (2000). Women's Development and NGOs. Rawat publications, New Delhi.

[2] Kothari. C. R. (1992). Rural Development: Admn. \& Tribal Welfare. Amazon. in (2 Vols), New Delhi, India.

[3] Clark J. (1991). Democratizing Development: The role of Voluntary organization. Conn Kumarian Press, London.

[4] Dimock, M. E and Dimock, G.O. (1964). Pubic Administration. Holt, Rinehart and Winston Inc., New York, 517-518

[5] Kumar Jitentder. (1988). Rural Development \& Poverty Alleviation. Health Educational And social Welfare Society. All India Urdu Publishers And Book Sellers Association, S-19052.

[6] Kumar R. (1992). Social \& Preventive Health Administration. Rawat publication, New Delhi.

[7] Kumar, Harish. (2000). Rural and Tribal Welfare and Development. Allied Publishers Limited, New Delhi.

[8] Lawani, B.T. (1999). NGOs in development. Rawat Publications, New Delhi

[9] Lewis David \& Wallce Tina. (2003). Development NGO's and the Challenges of change new roles and relevance. Rawat Publication, New Delhi.

[10] Rajasekhar, D. (1999). Decentralized Government and NGOs Issues, strategies and ways forward. Concept Publishing company, New Delhi.

[11] Srinivas Institute of Rural Reconstruction Agency SIRRA (2014), Journal by Srinivas Institute of Management Studies, Mangalore, Karnataka, India. 